\title{
Metallic Compounds of Protein
}

\author{
By Prof. Fritz Lieben, Vienna
}

TH $\mathrm{HE}$ experiments of which an account is given below were all made in co-operation with $\mathrm{Dr}$. Hans Jesserer in the Institute for Medical Chem. istry, University of Vienna. The work has been based upon the study of the biuret reaction of proteins, which has been known since 1833 ; thus all the experiments have been carried out in an alkaline medium, and it is to the latter alone that our results apply.

If a 20 per cent solution of copper sulphate is added to a casein solution in 3 per cent sodium hydroxide and the precipitate of copper hydroxide thus formed is filtered off, a solution of the wellknown violet colour results, the intensity of colour being proportional to the concentration of protein and thus obeying the Beer-Lambert law. It has further been found that the intensity of colour of the protein solution used is completely independent of the nature of the protein, provided that the concentration of the protein solution is always the same; hence the intensity does not depend on the kind of amino acids of which the proteins are built up. The amount of copper contained in the samples, calculated for an equal quantity of protein, is the same throughout.

The intensity of colour is also unaffected by the disintegration of the protein to peptone during the digestion of fibrin by pepsin; during this process the intensity of the colour produced in the biuret reaction remains completely unchanged after five or six days.

It is of further interest that the violet tint of the biuret reaction is not a single colour but consists of two components, one red and one blue. The extinction coefficients observed with the aid of the Pulfrich Stufenphotometer, and plotted as a graph against the number of drops of copper sulphate solution added, do not result in parallel straight lines for the red and the blue colour, but in straight lines meeting at an angle. The red component, like the full colour, is of equal intensity for different proteins in solutions of equal concentration. The mutual independence of the colour components is also shown by the fact that when a violet colour test is diluted with the protein solution used, the colour is shifted towards red, the copper atoms obviously taking the place in the protein chains necessary for the formation of the red component; the violet coloration, on the contrary, remains completely unchanged when the solutions are diluted with 3 per cent sodium hydroxide. In no case is the variation of the colour above mentioned due to different valence of the 'red' and 'blue' copper. When acidified, both colours completely disappear, but can be produced again by renewed alkalization; if ammonia is used for this purpose instead of sodium hydroxide, the well-known deep blue complex-colour is produced, which ean be used for the colorimetric determination of the bound copper. By gradual addition of copper sulphate, the red component alone is obtained, the blue not appearing until a given number of drops of the reagent is reached.

The Italian chemist Hugo Schiff, who was one of the first to study the biuret reaction (also for proteins) states that nickel as well as copper with protein in an alkaline medium shows a characteristic golden-yellow tint. It was therefore of interest to investigate, first the nickel, and afterwards the cobalt compounds of proteins. The colour of the latter samples is reddish-brown. Here the quantitative relations in comparison to those of the copper samples are noteworthy.

According to our experiments, $0.5 \mathrm{gm}$. of casein combines with $56.7 \mathrm{mgm}$. copper, thefull violet colour consisting of both the red and blue components ; correspondingly, $26.1 \mathrm{mgm}$. nickel and $17.4 \mathrm{mgm}$. cobalt respectively are bound under analogous experimental conditions. Taking the atomic weights of these three metals into consideration, it may be seen that two atoms of copper correspond to one atom of nickel, and three atoms of copper to one atom of cobalt. These simple proportions are easily demonstrated by adding two of the above-mentioned metals one after the other, to the same protein test solution. In this case the order in which the addition is made is of importance; when nickel or cobalt is added to a copper sample, one atom of the added nickel displaces two atoms of copper ; and one atom of cobalt, three of them; so that it becomes evident that nickel requires twice and cobalt three times the space taken by copper. If, however, the test solution contains nickel or cobalt from the first, and copper is then added, no displacement at all takes place, copper occupying the places still left free by nickel or cobalt ; that is, one atom of copper is added to every atom of nickel and two atoms of copper to each atom of cobalt; finally, as many places are occupied in the protein chains as in the tests with copper alone. 
Conditions become more complicated when the investigation is extended to the silver protein compounds in alkaline medium ; for here there is a tendency to keep larger quantities of the metalevidently in a colloidal form-in solution. Investigations appropriately applied, however, make it possible to reduce the quantity of silver present in the solution after filtration of the silver oxide to about $100 \mathrm{mgm}$. per $0.5 \mathrm{gm}$. casein, while the quantity of silver equivalent to $56.7 \mathrm{mgm}$. copper amounts to $97 \mathrm{mgm}$. So we have here one atom of silver for each atom of copper in the protein solution.

With gold the conditions are strikingly similar to those with cobalt. The quantity bound by $0.5 \mathrm{gm}$. casein amounts to $58.5 \mathrm{mgm}$. gold; this means, taking the atomic weights into consideration, that three atoms of copper correspond to one atom of gold. If copper is afterwards added to a sample with gold, the gold (as was the case with nickel and cobalt) becomes concentrated into a smaller space, but is not displaced, and two atoms of copper are added again to each atom of gold. Yet other similarities between gold and cobalt are that the test solutions in both cases must stand for several days to give the above-mentioned constant values, and furthermore that both these metal solutions are resistant to addition of acid, thus differing from copper (see above) and nickel solutions, which are thereby caused to disintegrate at once.

Different from the group copper, silver, gold, nickel and cobalt, all of which produce protein compounds in an alkaline medium, is another and larger group the members of which give no protein compounds under our experimental conditions. To this group belong, among other metals, iron, manganese, zinc, mercury, etc. We shall, however, not linger over this group.

A few words may be added on the point of linkage of metals belonging to the first group. Most probably this occurs at the nitrogen atoms of the peptide linkages. This supposition is based, among other reasons, upon the results of methylation ; for the number of methyl groups combined with nitrogen is reduced by the presence of the metal in copper-, nickel- and cobalt-protein solutions, in each case by about one third.

New experiments by Dr. Jesserer show that the precipitation of proteins with copper, etc., in neutral or acid medium takes place in the same way and that as much fresh copper is bound if the alkaline metal compound described above has already been produced, as in cases of native protein solutions. The copper, etc., added in acid medium must therefore be located at a different place from the metal in alkaline conditions, and as, very probably, only the carboxyl groups can be regarded as the place of location for the copper in the former conditions, the only place left for the metal in the latter conditions is the imino- and amino-groups.

A number of questions, significant both chem. ically and therapeutically, which have only been hinted at here, arise from the investigation of metallic protein compounds, which can easily be obtained in a dried state and are soluble in water. The investigations, which I still hope to carry on, must be continued in diverse directions ; among others, the catalytic powers of these substances must be examined.

\section{The Prosobranchs of Lake Tanganyika}

\section{By Prof. C. M. Yonge}

$\mathrm{W}^{\mathrm{H}}$ HEN Sir Richard Burton discovered Lake Tanganyika in 1858 his companion, Speke, collected a number of shells from the shores. These proved to be Prosobranchs of types hitherto unknown in fresh water. Later investigations, notably those of the three Tanganyika expeditions, the first two under the leadership of J. E. S. Moore $^{1}$ and the third under that of W. A. Cunnington ${ }^{2}$, revealed in fuller detail the remarkable nature of the fauna with its great number of endemic species of fish, Crustacea, sponges and, above all, prosobranch Gastropoda. Cunnington lists 84 species of Gastropoda of which 76 are endemic. The majority, 72 species, are Proso- branchia and of these 68 are endemic. Moreover 58 species have a heavy, frequently ornamented, shell, in appearance much more like marine than freshwater species. Moore, elaborating a suggestion made originally by Günther ${ }^{3}$, regarded these, and the other endemic species, as a relict fauna, the descendants of a diverse collection of marine species which lived in this region when Tanganyika was, as he maintained, an arm of the Indian Ocean. He described them as "halolimnic" species.

In his book, "The Tanganyika Problem", Moore ${ }^{1}$ claimed in support of his theory that the shells of these Prosobranchs were more closely allied to certain Jurassic fossils than to any modern species. 